\title{
FUSION \\ II. BROADENING THE FIELD OF OBSERVATION
}

Paolo Fonda ${ }^{4}$

Abstract: This is the second part of the paper in which fusion is considered as one of the fundamental mechanisms of mental functioning, an essential element in every object relation - with variations only in the degree of participation - along with the component connoted by separateness. There is a continuous dialectic relationship between levels of fusion and separateness. Human beings are characterized by an extremely sophisticated and continuously changing boundary system.

This part of the paper focuses on some aspects of the role of fusion within the psychoanalytic relation, the mother child matrix, the group mental activity and the meta-ego dimension.

Keywords: fusion, separateness, psychoanalytic relation, motherchild matrix, groupality, meta-ego.

\section{Introduction}

In our relentless effort to understand better and then describe the fascinating but elusive multi-dimensional object that is the human mind, we are compelled to resort to little more than approximate metaphors. Indeed, in this work, I put forth yet another series of metaphors aiming to shed light on one of its sides - the process of fusion - and then try to consider its role in mental activity.

After focusing on the role of fusion in general in my previous article (Fonda, 2019), and especially on the dialectic between fusion and separateness as one of the basic mechanisms of psychism, I would now like to broaden the field of observation. Remaining within the realm of the fusional component, I

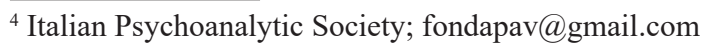


wish to make an overview of specific aspects of the psychoanalytic relation, the mother-child matrix, groupality, and of the more elusive, but no less important field for which I shall use the term meta-ego. That being said, I am not proposing an exhaustive examination of these fields. Instead, I intend to provide a quick look through the lenses that underscore the presence and activity of fusion, to outline a summary vision of the most ubiquitous fusional aspects.

\section{A. Fusion in the analytic relation}

I will consider some aspects of the role that normal fusion plays in the analytic relation, also due to the fact that analysts' attention has been nowadays increasingly focused on the analyst-patient relationship and its most hidden aspects. The intra-psychic has now been extended to the inter-psychic and the trans-psychic (Bolognini, 2008).

The heart of one of the debated issues in contemporary psychoanalysis could be: To what extent is the therapeutic effect the consequence of interpretations as such, which occur mainly at the more symbolic level (depressive position), and how much does this depend on the more relational aspects, which involve, to a greater extent the more basic levels of functioning (paranoid-schizoid and fusion positions)? This is a complex issue, partially because the answer must take into account various patient pathologies as well as what we truly mean by interpretation: is it that which aims to solve a conflict, or is it whatever gives words and representation to feelings and contents that had not previously been thinkable or mentalized?

In any case the communication of the interpretation inevitably occurs on all three levels, although in different proportions. Because different nonintentional communication modalities, which the analyst cannot avoid (such as infra-verbal and meta-verbal messages, emotional tone of the voice, word selection, pauses, body language etc.) are also involved, the symbolic content, despite often being central, will nonetheless be endowed with accompanying communicative projective identifications and flowing content.

Elaboration implies working mainly-but not only-on the third depressive level, characterized by both separation and the capacity for symbolization. Thus, interpretation helps the patient find a more appropriate setting among symbolic representations in the mental scenario. It fosters the passage to the third depressive level of content from the lower levels (paranoid-schizoid and fusion), in which concrete thinking prevails and where it had not been previously

\footnotetext{
${ }^{5}$ In the first part of this paper, published in the previous issue of this Journal (Fonda, 2019), the "three levels" were somehow connected to absence of borders-fusion (F), fragmentary borders-paranoid-schizoid (PS) and definite borders-depressive position (D). (I refer to the F-fusion position here as a sort of 'conglomerate' including Bleger's glischrocaric and Ogden's contiguous-autistic position.) 30
} 
possible for it to be adequately represented, processed, and used. This would then result in an outcome of beneficiary restructuring on all levels.

Nevertheless, interpretation, beyond its explicit value, also enables the patient to perceive that what the analyst thinks and feels in that very moment matches what is already present in him/her. This increases the area of coincidence and thus generates more intensive fusion and shared mental spaces. Therefore, interpretation is either a source of fusion or a resolver of fusion since it discriminates and symbolizes the elements by clarifying their belongingness. Facilitating the restructuring and resolution of painful conflicts at the end reduces the need for fusion in those determined areas.

The transference phenomenon, in general, can also be considered as an expression of the need of human beings to make the other - in a more or less illusionary way - more similar to what is already present inside of them, something that is already familiar and known. It is also an attempt to find and establish stronger coincidences that would open wider channels of communication. In the analytic context, such an attempt starts both from the patient and, to a lesser extent, from the analyst. This generates a relationship (though contrasted by resistances) where wider openings in the boundaries facilitate more extensive and profound communication on all levels. The transference neurosis is connected to regression, which widens the meshes of the borders of the self even more, increasing the paranoid-schizoid (narcissistic) position at the expense of the depressive one.

When we consider the analytic field, we presume that it implies an attenuation of the borders of the selves between the analytic pair and that, besides the patient's content, the analyst's content - including some unconscious parts - is also present, active and, in part, inevitably shared with the patient. Still, the analyst's transference is always taking place (although in a less intense and evident degree) and this unavoidably generates a certain counter-transference to it in the patient. The trans-subjectiveness of both is also present. The analytic third (Ogden, 1994) appears as a new common content.

The setting itself is also a source of fusion experiences for the patient, as it is characterized by reliable, coinciding repetitions. At the same time, the setting is a source of separateness because of its optimal frustrations (Fonda, 2000). Further fusional components of the setting frame are described by Bleger by means of his theory (1967b).

We may assume that the patient feels a need to share his suffering with the analyst in the same way that a child puts his wounded hand in his mother's in the belief that the best cure can only be achieved inside of her body, by being in fusion with her. Similarly, the patient is offering those areas of his self that, having suffered, need to be contained to be symbolized, represented and elaborated in less painful and more harmonious patterns. The analyst, by 
empathizing with this suffering is basically - although in a controlled manner 'letting it in'. It is a limited and partial fusion with this suffering that allows for a better understanding and a containment of it.

At the beginning of the analysis, the patient feels that he has many such areas to be shared and contained. However, an extensive flowing of fusion areas would threaten overall fusion. The patient does wish this to happen, but, at the same time, is afraid of it. It generates fears of being trapped and of losing one's identity. Therefore these feelings produce intense resistances to such a relationship. By gradually overcoming this resistance, controlled, beneficiary and productive partial fusion begins to occur, and a re-balance takes place as containment-metabolism increases. The analytic relationship and interpretations tend to exhaust these needs of suffering areas and therefore diminish the need of fusion by reducing it to normal 'maintenance' levels.

Bonfiglio (2018), recalling Winnicott and other Authors considers the basic importance of the structuration of an analytic environment that would allow, or better favor, symbiotic/fusional processes, which must gain a central therapeutic role within the analytic situation, as a pre-condition for further developments.

Referencing this point, I would recall what I have said about the basic human need, when necessary, to expand one's boundaries to make mental contents extend beyond the narrow limits of one's individuality, as well as allow contents of others to flow in one's mind space. We can imagine that a channeled exchange, such as fusion, favors a certain harmonization and attunement of given areas of the inner worlds of two subjects. This could contribute to the establishment of the necessary conditions for further development and growth.

That being said, further development requires that a particular portion of shared floating, projected, or introjected content be picked up at the 'third level', being mentalized and given back to the patient by interpretation, by the containment process. If such containment is insufficient, a blocked symbiosis could indeed set itself up and perpetuate without leading to growth. It could only be traumatically interrupted. In such pathologic symbiosis, where functioning is significantly limited to fusion and paranoid-schizoid positions with prevailing concrete thinking, while the depressive position is insufficient, there is striking evidence of a continuous exchange-fluctuation of content and intensive projective and introjective identification activity. Nonetheless, the contents are not sufficiently discriminated in qualities and pertinence with one or the other of the two subjects.

Fusion itself does not achieve a sufficiently therapeutic effect if not combined - perhaps in different moments or stages - with interpretation and symbolic elaboration, which itself cannot leave aside separation. 
However, even symbolic elaboration cannot fully exercise its function if it does take place within a relational context where fusion doesn't play a significant role. Let's recall Ogden's (1989b) continuous "dialectic" interplay among the three positions (depressive, paranoid-schizoid and contiguous-autistic, which I connect here to fusion). We may consider as one of our main therapeutic goals to free and favor an optimal and dialectic interplay among the three positions, and within this also the interplay fusion-separateness.

\section{B. The mother-child matrix}

Continuing our hypothesis through the lens of fusion, it is worth dwelling on the initial, basic need of the child to establish and maintain a relationship with a human object that is sufficiently similar (not alien) to allow for generative coincidences of fusion, which in the earliest stages are virtually the only way to generate relation and communication. The child turns to its mother looking for skin-to-skin contact (along with olfactory and auditory contact), and maternal preoccupation tends to make that contact as coincident as possible, that is, fusional. Erogenous zones provide for privileged occasions for contactcoincidence-fusion of particular intensity.

In Winnicott's schema in which the breast is offered at the right moment when internal need takes shape, there is perhaps a forerunner of the coincidence (syntonic-pleasurable) that generates fusion. This is limited from the outset by (optimal) frustrations constituted by non-coincidence (dystonic-displeasing), and the difference between the internal and the external, which tend instead to trace an outline of boundaries, that is a (pre) object experience of separateness.

As the child has little tolerance for separateness, which is a source of the anxiety of powerlessness up to the fear of breakdown (Winnicott, 1962, p.37), the mother takes care to coincide as much as possible, thus extending the fusional part of the relationship. Here we find both partial fusional elements that actually exist (mental sensations) and fantasies of fusion (mental representations), such as the illusion of omnipotent union. The latter spread in the child with the development of the capacity to represent and can take the path of symbolization or stagnate in concrete thought. Such stagnation makes separation problematic and leads to pathological bonds of permanent symbiotic nature.

Throughout these processes, the mother's ability to use symbolic thought and foster the same skill in the child is fundamental. This runs parallel to the consolidation of the depressive position and the ability-possibility to experience the relationship on both a fusional level as well as on the level of separateness.

So, in the early stages of life, a widespread but not exclusive sensation of global fusion tends to take shape. This sensation then lessens with the discrimination that is implementing separation thanks to the combination of 
optimal frustrations during the process of "weaning" (Winnicott, 1953, p. 95) and "separation-individuation" (Mahler, 1963). In all of these, a primary role is played by "containment" (Bion, 1962).

Be that as it may, it is essential that - besides the capacity to coincide with her child and to maintain the fusional level of the relationship - the mother is also able to not coincide at times, and at others to accept, support, and develop the child's capacity not to coincide. Here the mother's capacity to accept and tolerate the paradox of being one - fused - with her child, while at the same time being separate, comes into play. This maternal ability takes on an organizing function toward the child, allowing it, too, to develop the fundamental capacity of experiencing object relations on two sides at the same time, the fusional and the separate (or better, in all three positions simultaneously, as described in my previous article, Fonda, 2019). Kafka (1989, p.43) emphasizes how fundamental to the child's development is the mother's ability to tolerate the ambiguity of meaning, the contemporaneity of multiple, contrasting meanings, and to transfer that ability to her child, allowing him to experience "multiple realities". This would provide the child with "a solid anchor to a single reality, along with the capacity to embrace multiple realities".

These complex and delicate mechanisms, which lead to the acquisition of fundamental psychic structures, can only occur in a close and unique relation with one object, later followed by multiple objects that are sufficiently similar, with which partial fusional relations can be established through shared mental spaces. This allows for a fuller response to the urge for the autonomy of mental functioning.

Infant research (Stern, 1983) indeed provides data on the early presence of specific functions of newborns. However, infants don't have the autonomy that such functions seem to imply. Newborns have an innate capacity to distinguish between themselves and others. Yet this does not mean that they can differentiate between their first schema of self and that of others, or between representations of the self and of the object. In this context, though they are functionally connected, it is necessary to distinguish between the neuropsychological level - closer in nature to neurological hardware - from the representational level more pertinent to psychological software. A newborn child would indeed be able to perceive the other, but would not yet be able to represent it, much less represent the relation between the self and the other. This type of representation is fundamental to mental life.

Kumin (1996, p. 27) states: "While children have the innate cognitive ability to distinguish between sensitive-motoric experiences of themselves and of the other, such ability can paradoxically be generated and supported by the not perceived supporting environment, in an ample way undifferentiated, that is provided by the good enough mother". The first fragments of differentiation 34 
and separateness can therefore develop thanks to the substrate of fusional undifferentiation given by the mother-child matrix.

This is a complex framework where, from the beginning of life, neurological substrate, and mental dimensions coexist and complete one another. Moreover, concerning the mental dimension, we find pre-object and object elements, fusion and separateness (and a bit later) concrete and symbolic thought in a developing integrated vision that Ogden (1992a,b) would call dialectical.

We may imagine the mother-child relationship with the child experiencing both the sensorial presence of the mother and her mental functioning as if, to $a$ certain degree, they were present within himself (or better: within the partially undifferentiated mother-child union). Being partially inside (due to fusion) is also essential for the mother. It allows her to grasp messages and nuances from inside the child, which would otherwise go unperceived. But real empathy in the mother is only possible if there is sufficient separateness in her at the same time. If not, then the result is a con-fusion.

Fusional spaces with wide mesh allow for the diffusion and projection of raw content (beta elements) from the child to the mother. Only the subsequent use of her separate parts enables the completion of both the processes: empathy and containment.

But fusional channels are not one-way streets. Although it occurs in a variety of proportions, there is also a passage of undifferentiated elements from caregiver to child. This is of interest because, besides providing the child with a set of useful elements, it can also convey elements that could cause distortions in the child's development. It could involve the caregiver's malfunction or pathology, as well as the transmission of transgenerational content, including both individual and collective traumas.

Although we will not deal with this issue here, it raises the question of what and how much of the analyst's content passes to the patient that is beyond the analyst's conscious control.

At this stage, because the inside and the outside may be only vaguely perceived, the child experiences what happens in the mother - the function of affect and drive regulation and containment - in part, as also happening inside of him/her. This would create the optimal situation to induce the surrounding parts of the infantile self - fortuitously genetically predisposed to early maturation - to carry out the same functions. In such circumstances, the more precocious aspects of the imitation-introjection-identification would occur (Gaddini, 1969). The object's functioning would find the child ready to imitate-introject, ready to 'duplicate'.

A tennis instructor holds a student's hand and accompanies him as he swings the racket. The student is eager to imitate-learn. The author of the 
movement is initially the instructor, forcing the rough awkwardness of the student's lack of muscular coordination. However, as time passes, the creator of the action becomes increasingly indistinct as their two movements coincideas they 'fuse'. At this point, once fusion has occurred, fusion itself is no longer necessary, at least on a concrete level. The instructor's hand may be withdrawn, and the student now feels his movement as entirely pertinent to his own self. All of this passes through a necessary transitory phase of partial fusion, where neuronal circuits are constituted in the student (these circuits coincide with those that already exist in the instructor), which allows motor patterns to be consolidated. Identification will then be established where, following imitation and introjection, a part of the fusion is conserved (the student always feels a bit like the instructor, even if he plays alone). But now the remnants of fusion are being executed with the internal representation of the instructor and not with the actual instructor.

And so, alongside and due to the maturation of the neurological substrate and the preconditions for the structuring of an increasingly functional ego, the child experiences a slow duplication of the maternal apparatus to think thoughts (within the process of internalization of the primal object). In its real concreteness, this would eventually be progressively separated-extracted from its shared matrix.

This will be the less traumatic and more enriching the need and pleasure of autonomy, the more complete and functioning is the introjection of the relationship with the primary object, the installation of the program to think thoughts. It will allow for self-containment, self-regulation of affects and drives, and ultimately provide for the living of a self-sufficient life.

The emancipation, also in normality, will never be complete because - as Kohut (1971) reminds us - despite the fact that it attenuates and diversifies, the need for self-objects never truly disappears during life.

When the object relation is 'installed' the emotional relational atmosphere comes with it. It establishes affinities (including cultural ones, if we consider a broader context) that make coincidence and, therefore, reattachments easier whenever needed. Furthermore, those affinities direct the search for similar objects (especially those that have a self-object function) in later stages (e.g. partners).

What has been set forth so far should bring to mind how premature separation - whether physical or emotional - runs the risk of severing the fusional channels of a relationship when they are still functioning heavily and vital to complete the structuring of the child's mental apparatus. It is tempting to imagine that the profound and painful sensation some adult patients complain of when they say that life "owes them a debt that is never paid" may indeed have some roots in similar, early traumatic disruptions. 


\section{Groupality}

The mental activity of groups appears replete with fusional aspects. If we deem valid the hypothesis of fusional channels as a network, we can imagine that network as contributing to a constant synchronization of group content. This is a necessary condition for maintaining adequate cohesion and the functionality of the group. The very foundation of the life of the group, that is, the basic shared project among members, involves an experience that is not entirely separate in single individuals. Indeed, it would seem contrived to consider an individual's mental activity as entirely separate from that of the group.

In Freud's (1921, p. 123) "Group Psychology and the Analysis of the Ego" he states that: "We must conclude that the psychology of groups is the oldest human psychology; what we have isolated as individual psychology, by neglecting all traces of the group, has only since come into prominence out of the old group psychology, by a gradual process which may still, perhaps, be described as incomplete." (my underlining)

And still (Freud 1921, p. 129): "Each individual is a component part of numerous groups, he is bound by ties of identification in many directions, and he has built up his ego ideal upon the most various models. Each individual therefore has a share in numerous group minds-those of his race, of his class, of his creed, of his nationality etc. - and he can also raise himself above them to the extent of having a scrap of independence and originality." (my underlining)

Significant fusion in the life of the group is the starting point. From here, features of individuality struggle to emerge. In Europe, after an emancipatory movement of the individual achieved a high level of excellence in ancient Greece and Rome, it then regressed. We would have to wait for the Renaissance to restart the processes by which individuals somewhat emancipate themselves from a high degree of fusion with the group (Fonda, 2015).

In this sense, if we compare the group-individual and mother-child relationships, both a child and an individual are insufficiently emancipated and partially fused with whoever and whatever surrounds them. This occurs despite having also developed numerous ego functions that allow them to distinguish some features of the world around them. However, a large part of their thinking and feeling does not differ from their environment. It is as if they lay in wait for their life or historical circumstances from which they could broaden their self-awareness and proceed down the path of individuation.

The metaphor that springs to mind is of an individual with a boundarynet. It contains specific features of his/her individuality and can be shaped by an increasingly narrow mesh-border. But it is immersed in a liquid (the 
psychism of the group) that flows and crosses it, soaking the content of the net with the substances that are dissolved in the liquid. As in a semi-permeable membrane, specific circulating substances pass through without difficulty; some are actively absorbed, while others still are blocked at the entrance or even expelled.

It is as if the individual had to 'breath' and 'feed' his/her 'psychic metabolism' also through fusional channels. In doing so, he/she, though mostly unaware of this, makes use of that enormous repository of myths, codes, experiences, proto-knowledge and proto-memories that make up the basis of the culture of every group and humanity at large. We swim in a primordial sea, which we have shaped as sapiens since the Great Leap Forward (Moreno, 2018, p. 167) in prehistoric times. We absorb and use its content as well as introduce our own experiences into it, changing it both positively and negatively. It is mainly by fusion that we link to this 'i-Cloud' where our culture has been deposited over many thousands of years. Much of this happens unconsciously and seems to connect back to the unrepressed unconscious. More than an ocean, it appears to be a system of intercommunicating lagoons-groups, starting from the smallest of groups, the family, and even the analytic couple with its field.

In individual analysis, there is little focus on the influence of unconscious fantasies on a group-cultural level (such as myths and collective ideals). These are active from the beginning of life through the parents and then more directly as the child is exposed to the social environment. They also serve to satisfy the needs of group functionality, which insists on the upbringing of individuals where certain personality characteristics are amplified and others are reduced. It suffices to imagine how different the image of a 'good-enough child' in our group and the minds of parents today is in contrast to what was prevalent in our same group 50 or 100 years ago (not to speak of different cultural areas). Just imagine how many different ways of managing drives and affects there used to be in child upbringing. So, not only can we say "how much our patients have changed" (Gaddini, 1984), but also "how much our children have changed" and consequently also adults.

These and similar elements of groupality are examined with significantly different competencies by group analysts and psychoanalytically oriented anthropologists. However, individual analysts often go to great lengths to resist the integration of findings from these fields. Though - for example - Kaes (2007), as well as other group analysts, have given significant contributions in connecting individual analytic thinking and clinical work to group analytic findings.

Nevertheless, we may think that there could be, for any historical and cultural environment, an optimal balance between the level of individuation and the part of the psychic activity merged in the group. Perhaps in some areas, as in today's Europe, the level of individuation could be so high that it may 38 
create a threat of fragmentation of the group. This results in making it more difficult to find a sufficient group cohesion even on shared projects that could be necessary for the survival of larger groups. An excess of diffuse individuation and the consequent threat of fragmentation or disintegration of large groups, like nations are, may then give rise to catastrophic anxieties, which could provoke the need to seek refuge in rigid (and perhaps dangerous) paranoidschizoid positions, where merging in a common ideology or faith may provide cohesion and force.

\section{Meta-ego}

To give a further look to the area where fusion plays a significant role I shall now use Bleger's (1967a) term meta-ego and just mention few Authors, whose concepts on this issue appear partially overlapped. This area includes undifferentiation, non-mentalization, the undefined belonging to the me or not$m e$ and perhaps the at least partial pertinence to the unrepressed (structural) unconscious.

As early as fetal life, the mnestic traces of sensations start to accumulate. These then constitute a vague and undifferentiated entity, later enriched by sensations outside of the uterus, connected with a state of being as a state of unintegration (Winnicott, 1948, p. 25): "In the quiet moments there is no line between inner and outer but just lots of things separated out, sky seen through trees, something to do with mother's eyes all going in and out, wandering around. There is a lack of any need for integration." (my underlining). And furthermore (Winnicott, 1952, p. 99): "[...] the unit is not the individual, the unit is an environment-individual set-up. The centre of gravity of the being does not start off in the individual. It is in the total set-up". This contrasts the traditional image that after the beginning of life there is a certain point in development where the individual mind progressively opens to the world and begins to test and penetrate it with its 'pseudopods'.

Bleger (1967a) goes further this way with his notion that the child comes from a total, initial immersion in the undifferentiated, non-discriminated world, in which what he calls the primordial glischrocaric position prevails. The psychic development part of this content, thanks to the activation of the paranoid-schizoid position, is discriminated by the ego and integrated. But a large undifferentiated, undiscriminated, ambiguous part remains split and is deposited onto external objects, playing then an important, though mainly silent, symbiotic role.

We may suppose that this symbiotic deposit, though split from the ego, may give to these parts of the external world, on which is deposited, some familiar flavor, as it has not yet been cleared its belonging to the me or not-me. 
This deposit, called also meta-ego, which is set up in the undifferentiated encounter-overlapping between the internal and the external, also bridges the internal and the external reality. Through this bridge, the external would be imbued with the internal and vice-versa. Both would then result sufficiently similar to be - to a certain extent - silently bond together (though remaining split). This may be not only a component of the relation with primary objects, the group, and its culture, but with reality tout court, including the inanimate part of it.

It is as if we are encircled by a large ring or halo which we must deposit upon everything around us in order to feel supported. Without doing so, instead of 'floating', we would sink into a dimension of solitude incompatible with life.

This 'interface' is also formed by contents, among others, which are conveyed by 'diffusion', first from parents and then by ever-expanding social environment. The presence of these shared elements should facilitate the mute connection-bond to the psychism of the individual with human objects, with the unconscious cultural foundation of various groups, with their more general meta-ego.

For Ogden (1989a) the autistic contiguous position is the psychological organization generating the most primitive state of being. It is also difficult to locate the content of these pre-object ways of mental functioning in relation to the boundaries of the self. As they are lacking in a sufficient distinction between what belongs to the subject and what belongs to the outer world, they seem to refer to a primordial mainly fusional space too. "This primitive psychological organization under normal circumstances contributes to the barely perceptible background of sensory boundedness of all subsequent subjective states."(Ogden, 1989a, p. 128) But Ogden emphasizes the clearly dialectic essence of this, as well as the other two positions: "It must be borne in mind [...] that an autisticcontiguous mode of experience does not exist in pure form any more than one encounters paranoid-schizoid or depressive modes in pure form. Each of these modes represents a pole of a dialectical process between which experience is generated. The autistic-contiguous mode [...] serves to generate the sensory 'floor' (Grotstein, 1987) of all experience" (ibidem, p.136). Here we also reencounter, although in different forms, the constant interplay between fusion and separation.

In his article on setting, Civitarese (2004) examines specific conceptualizations close to what here I refer to as meta-ego. He reiterates Ogden's idea of returning 'dignity' to this part as a 'healthy' component that is normal and necessary for the human psyche during the whole life. Ogden frees it from the residuals of a pathological connotation, which Bleger still referred to as 'psychotic'. It would be overly simplistic to consider it a useless remnant of primordial life, only an undifferentiated agglomerate waiting for 'refinement', or a dangerous ballast that risks overflowing and leading to psychotic regression. 40 
Civitarese (2004, p. 1134) holds that the meta-ego carries out essential functions, including the guarantee of the continuity of being. "Surprisingly, the psychotic part appears first as the guardian of a sense of continuity of the self (the meta-ego or the 'frame' of the ego), and then as helper that knows how to manage certain situations which arise when the ego is confronted by the danger of dissolution".

"The subject thus apparently needs to experience reality in a 'presymbolic, sensory-dominated' mode (Ogden, 1989b, p. 30) - to structure symbiotic bonds and links, even in adulthood, as guarantors of identity." (Civitarese, 2004, p. 1136)

"... patients in the analyst's consulting room bear witness to the state of this symbiotic life of theirs - their meta-ego - to the humps and bumps of the 'ground', and to the general conditions of solidity and reliability of their 'floor'. In some, the constant need for reparation proves obsessive, given the extent to which this sensory floor is felt to be damaged..." (Civitarese, 2004, p. 1138)

A 'solid' meta-ego contributes to the establishment of reliability. In Winnicott's vision (1971, p. 109), this is one of the underlying conditions upon which potential space can take shape and where optimal frustrations may generate symbolic representations. A mother-child couple could function well enough only if the two have a solid ground on which to stand.

In suitable doses, the meta-ego could also perform a protective action, 'diluting' the effect of the harsh, direct contact with reality and with its unrelenting laws. Indeed, if conflict becomes unsustainable, we may immerse parts of our self in the murky waters of ambiguity, within which irreconcilable contradictions can co-exist without conflict and without giving rise to unbearable anxieties. Bleger (1967a) described as such when he wrote of ambiguous personalities. Likewise, we may resort 'normally' - temporarily or not - to a dose of ambiguity to dilute conflicts, allowing us to live with them. This occurs in much the same way that we can quietly savor (without conflict) a delicious meal in a restaurant, despite knowing - but 'ambiguously' not thinking (perhaps splitting) - that in the same moment millions of children are starving. This also connects us to reflections on more general vicissitudes of ethics.

An analogous example we may find in clinical observations on the experience of time. As it is closely linked to the inevitability of death, we necessarily relate with it through certain filters, like could be ambiguity offered by the meta-ego. Indeed, there is an absence of time boundaries on certain levels of our Self. Time is thus made bearable as - to a certain extent - 'ambiguously' we feel that the inevitability of death and the fantasy of eternal life are not, in fact, contradictory. Narcissism seems broadly connected to the meta-ego and to ambiguity, which allow it (narcissism) to take refuge in atemporality and omnipotence (absence of power boundaries). 
All of this is connected by the fact that there are inevitably certain limits to what we can bear and integrate. When we risk exceeding these limits and suffering a breakdown, we are forced to immerse ourselves more deeply in the undifferentiated and the ambiguous.

In a similar vein, Jaques already in 1955 wrote that the psychosis of the group could safeguard individuals from psychotic collapse. Participating in the psychism of the group offers the possibility to be contained, to use codes, patterns, knowledge, and affiliations that keep isolation at bay, while the metaego would mainly provide continuity and stability.

Bleger (1967a, p. 216) refers to something similar: "Upon the occurrence of highly persecutory situations which the subject cannot face because he would otherwise be plunged into total disorganization or a state of psychotic dissolution, he blurs the contradiction or persecution he is experiencing and regresses to ambiguity".

A group has its own meta-ego as well, located below levels of representability. Certain vital changes in the conditions of life can give rise to adaptive cracks even in such deeper 'geological' layers, leading to faults within the meta-ego. Catastrophic anxiety can then be triggered, which is managed both on a group and on an individual level.

\section{Conclusion}

These notes and comments are brief and incomplete. I wished to highlight an overall image of the individual and his/her mental apparatus where, despite having parts of the self that are well and truly separate and individualized, others are profoundly fusionally connected to what surrounds him/her, often through mostly silent connections.

In other words, we are 'amphibious', staying knee-deep in the waterfusion through our entire lives. Be that as it may, this is not an unhealthy state from which we must cure ourselves, but rather a gift from nature. It allows us not only to survive, but to live life more fully. At times, we may perceive this background even with pleasant nuances, akin to an "oceanic feeling". But this feeling could be understood more in Romain Rolland's creative sense rather than Freud's purely regressive meaning (Saarinen, 2012).

Our responsibility as analysts is not to free the individual from fusion, but to make the sway between separateness and fusion as free and serene as possible so that it may be optimally adjusted in either direction. It would be a challenge for us to devise techniques for further improving and balancing such interactions, taking into account all of the elements at play. 


\section{REFERENCES}

BION, W.R. (1962). Learning from experience. Heinnemann, London.

BLEGER, J. (1967a). Simbiosis y ambiguedad, estudio psicoanalitico [Symbiosis and ambiguity]. Editorial Paidos, Buenos Aires.

BLEGER, J. (1967b). Psycho-Analysis of the Psycho-Analytic Frame, Int J Psychoanal, 48:511-519.

BOLOGNINI, S. (2008). Secret Passages. The theory and Technique of Interpsychic Relations. Routledge, London, 2010.

BONFIGLIO, B. (2018). Simbiosi/Fusionalità e costruzione della soggettività. [Symbiosis/Fusion and Construction of Subjectivity]. Franco Angeli, Milano.

CIVITARESE, G. (2004). Vincolo simbiotico e setting [The symbiotic bond and the setting], Riv Psicoanal, 50(4):1117-1147.

FONDA, P. (2000). Rivisitazione di alcuni versanti del setting [Rivisiting Some Sides of the Setting], Argonauti, 85:137-150.

FONDA, P. (2015). The Opening of Psychoanalysis to New Cultures: Creating a Space for Individuation and the Need for Psychological Help. Presented at the IPA International Congress, Boston, 23 July 2015.

FONDA, P. (2019). Fusion I. One of the Basic Mechanisms of the Human Psyche, Rom J Psychoanal, 12(2):38-56.

FREUD, S. (1921). Group Psychology and the Analysis of the Ego. SE XVIII. Hogarth Press, London, pp. 65-144.

GADDINI, E. (1969). On Imitation, Int J Psychoanal, 50:475-484.

GADDINI, E. (1984). Se e come sono cambiati i nostri pazienti fino ai nostri giorni [If and How have Changed our Patients till Nowadays], Riv Psicoanal, 30:3, 560-580.

GROTSTEIN, J. (1987). Schizophrenia as a Disorder of Self-regulation and Interactional Regulation. Presented at the Boyer House Foundation Conference: The Regressed Patient, San Francisco, 21 March 1987.

JAQUES, E. (1955). Social Systems as Defence against Persecutory and Depressive Anxieties. In: New Directions in Psycho-Analysis. Tavistock Publications Ltd, London.

KAES, R. (2007). Un singulier pluriel. La psychanalyse à l'epreuve du groupe [A plural singular. Psychoanalysis group tested]. Dunod, Paris. 
KAFKA, J.S. (1989). Multiple Realities in Clinical Practise. Yale University Press, London.

KOHUT, H. (1971). The Analysis of the Self. Hogarth Press, London.

KUMIN, I. (1996). Pre-Object Relatdness: Early Attachment and the Psychoanalytic Situation. Guilford Press, New York and London.

MAHLER, M.S. (1963). Thoughts about Development and Individuation, Psychoanal St Child, 18:307-324.

MORENO, J. (2018). The Origin of Humans. EPF Bulletin, 72:167-164.

OGDEN, T.H. (1989a). On the concept of an autistic-contiguous position, Int J Psychoanal, 70:127-140.

OGDEN, T.H. (1989b). The Primitive Edge of Experience. Jason Aronson Inc, New York.

OGDEN, T.H. (1992a). The Dialectically Constituted/decentred Subject of Psychoanalysis. I. The Freudian Subject, Int J Psychoanal, 73: 517-526.

OGDEN, T.H. (1992b). The Dialectically Constituted/decentred Subject of Psychoanalysis. II. The Contributions of Klein and Winnicott, Int $J$ Psychoanal, 73:613-626.

OGDEN, T.H. (1994). The Analytic Third: Working with Intersubjective Clinical Facts, Int J Psychoanal, 75:3-19.

SAARINEN, J.A. (2012). The oceanic state: a conceptual elucidation in terms of modal contact, Int J Psychoanal, 93:939-961.

STERN, D.N. (1985). Il mondo interpersonale del bambino [The Interpersonal World of the Infant]. Bollati Boringhieri, Torino, 1998.

WINNICOTT, D.W. (1948). Primary Introduction to External Reality: The Early Stages. Talk given at the London School for Economics.

WINNICOTT, D.W. (1952). Anxiety Associated with Insecurity. In: Through Paediatrics to Psycho-Analysis. The Hogarth Press and the Institute of Psycho-Analysis, London, 1975.

WINNICOTT, D.W. (1953). Transitional Objects and Transitional Phenomena - A Study of the First Not-Me Possession, Int J Psychoanal, 34:89-97.

WINNICOTT, D.W. (1962). The Theory of the Parent-Infant Relationship - Further Remarks, Int J Psychoanal, 43:238-239.

WINNICOTT, D. W. (1971). The place where we live. In: Playing and Reality. Basic Books, New York. 